\title{
DISPOSITIVOS CONSTITUCIONAIS ATINENTES AOS DIREITOS DAS PESSOAS COM DEFICIÊNCIA
}

\author{
CONSTITUTIONAL PROVISIONS REGARDING THE RIGHTS OF PEOPLE WITH DISABILITIES
}

\author{
Lucas Marin Cebrian ${ }^{1}$ \\ Perci Fábio Santos Fontoura ${ }^{2}$ \\ Pedro Henrique Marangoni ${ }^{3}$ \\ Renan William de Deus Lima ${ }^{4}$ \\ Luiz Roberto Prandi ${ }^{5}$
}

'Bacharelando em Direito e participante do Programa de Iniciação Científica da Universidade Paranaense - UNIPAR.

E-mail: lucasmarincebrian@hotmail.com

${ }^{2}$ Bacharelando em Direito e participante do Programa de Iniciação Científica da Universidade Paranaense - UNIPAR.

E-mail: fabio_perci@hotmail.com

${ }^{3}$ Bacharelando em Direito e participante do Programa de Iniciação Científica da Universidade Paranaense - UNIPAR.

E-mail: phmgoni@hotmail.com

${ }^{4}$ Bacharelando em Direito e participante do Programa de Iniciação Científica da Universidade Paranaense - UNIPAR.

E-mail: renan_limadir@hotmail.com

${ }^{5}$ Doutor em Ciências da Educação/UFPE. Mestre em Ciências da Educação UNG/SP. Especialista em: Metodologia do Ensino Superior, Gestão Escolar, Educação do Campo, Educação Especial, Gestão Ambiental, Lengua Castellana, Metodologia do Ensino de Sociologia e Filosofia e Gênero e Diversidade no Espaço Escolar. Membro do Comitê Assessor Local de Iniciação Científica - CALIC/UNIPAR. Professor titular e pesquisador na Universidade Paranaense - UNIPAR. E-mail: prandi@prof.unipar.br

Recebido em maio de 2016 Aceito em outubro de 2016
CEBRIAN, L. M.; FONTOURA, P. F. S.; MARANGONI, P. H.; DEUS LIMA, R. W. de; PRANDI, L. R. Dispositivos constitucionais atinentes aos direitos das pessoas com deficiência. Akrópolis Umuarama, v. 25, n. 1, p. 25-34, jan./jun. 2016.

\section{DOI: 10.25110/akropolis.v25i1.6671}

Resumo: O respectivo estudo possuiu suas reflexões direcionadas sobre os dispositivos constitucionais atinentes aos direitos das pessoas com deficiência, bem como a natureza jurídico-constitucional destes. Deste modo, por meio de uma análise descritiva com uma abordagem qualitativa, o presente trabalho disporá sobre os artigos inseridos na Constituição Federal de 1988 que tratam sobre a situação das pessoas que, em virtude de suas limitações, possuem sua mobilidade, ou capacidade intelectual, reduzidas. Ainda será feita uma breve análise acerca do que se tratam os direitos e garantias fundamentais, bem como será levado em conta a importância do princípio da dignidade da pessoa humana dentro do ordenamento jurídico pátrio. Observa-se ainda que, como método de pesquisa, foi utilizado basicamente a pesquisa legislativa bibliográfica acerca da temática, com autores especializados no assunto. Por fim, feito o devido levantamento bibliográfico, concluiu-se que, em que pese parte destes dispositivos estejam situados fora do Título II da CF/88, ainda assim, podem ser considerados direitos fundamentais em virtude do princípio da igualdade.

PalaVRas-chave: Constituição Federal Direitos Fundamentais; Dignidade da Pessoa Humana; Pessoa com deficiência.

ABSTRACT: This study is directed towards the constitutional provisions regarding the rights of people with disabilities, as well as their legal and constitutional nature. Thus, through a descriptive analysis using a qualitative approach, this study will address the articles inserted in the 1988 Federal Constitution that deal with the situation of those who, due to their limitations, have mobility or intellectual capacity diminished. It will also present a brief analysis on fundamental rights and guarantees, as well as addressing the importance of the human dignity principle within the Brazilian legal order. It can also be observed that the research method used legislative literature review on the topic, and also literature published by expert authors on the matter. Once the literature review was completed, it could be concluded that, although part of these devices are not inserted under Title II in the 1988 Brazilian Federal Constitution, they can still be considered fundamental rights under the principle of equality.

KEYWORDS: Federal Constitution. Fundamental rights. Individual Dignity. People with disabilities. 


\section{INTRODUÇÃO}

No ordenamento jurídico pátrio há um debate acerca da natureza jurídica de determinadas normas, isto é, se elas são ou não direitos fundamentais. É de suma importância entender se uma determinada norma presente em nossa Constituição se trata de direito fundamental, haja vista que tais normas são tuteladas pelo § $4^{\circ}$ do artigo 60 da Constituição da República Federativa do Brasil de 1988.

Ao longo de nossa atual Constituição verifica-se vários dispositivos referentes às pessoas com deficiência, com alguns deles fora do Título II, que foi reservado para tratar especificamente dos direitos e garantias fundamentais. Dúvidas surgem pelo fato de nossa Constituição ter criado um título específico para tratar dos direitos e garantias fundamentais,.

Desse modo, teria o legislador constituinte criado então um rol taxativo de tais direitos? A reposta, por óbvio, só pode ser negativa. Conforme será exposto ao decorrer deste estudo, os direitos e garantias reservados as pessoas com deficiência, ainda que dispostos fora do Título II, são considerados fundamentais, uma vez que tal rol não deve ser interpretado como taxativo, mas sim como exemplificativo. E conforme alguns princípios que nossa própria Constituição estabelece, devemos entender tais normas como fundamentais.

Os princípios que fundamentam tal raciocínio são o da dignidade da pessoa humana e o da igualdade, tanto em seu sentido formal quanto material. O primeiro estabelece um patamar existencial mínimo para uma vida digna, ao passo que o segundo possui duas acepções, uma estritamente ligada ao princípio da legalidade e o outro com uma visão mais social, igualando os indivíduos de nossa sociedade.

O presente estudo possui, portanto, por objetivo analisar a incidência dos direitos fundamentais sobre os direitos atinentes as pessoas com deficiência, fazendo um contorno histórico pelos direitos fundamentais e utilizando os princípios basilares de tal como fundamento para a equiparação dos direitos das pessoas com deficiência aos direitos fundamentais.

Para o desenvolvimento deste estudo foram utilizados materiais bibliográficos, doutrinas e jurisprudências, bem como nossa própria Constituição.

\section{DIREITOS E GARANTIAS FUNDAMENTAIS}

A Constituição da República Federativa do Brasil, de 1988, reserva um Título especial para os direitos e garantias fundamentais. Trata-se do título II da Carta Magna, onde a previsão de tais direitos e garantias permeiam desde o artigo $5^{\circ}$ até 0 artigo 17 . Desse modo, nota-se uma atenção especial do constituinte no que tange aos direitos e garantias fundamentais. Não é a toa que, em virtude desta posição de destaque de tais direitos que a carta Magna de 1988 é conhecida por muitos como a "Constituição Cidadã".

É possível ainda, por meio de uma leitura das constituições anteriores, notar a relevância dada aos direitos e garantias fundamentais pela a atual Constituição Federal. Observa-se que, enquanto a atual Constituição dedica os primeiros dispositivos para tratar das garantias e direitos fundamentais, as constituições anteriores tratavam, inicialmente, da estrutura do Estado e organização do poder.

Como inicialmente mencionado, a atual Constituição Federal passa a tratar dos direitos e garantias fundamentais a partir do artigo $5^{\circ}$, onde se dá início ao Capítulo I, que trata dos direitos e deveres individuais e coletivos. Do artigo $6^{\circ}$ ao 11 , estão previstos os chamados direitos sociais. Ainda dentro do Título II, os artigos 12 e 13 tratam da nacionalidade, enquanto que os artigos 14,15 e 16 dizem respeito aos direitos políticos. Por fim, ainda dentro do Título reservado aos direitos e garantias fundamentais, encontra-se o artigo 17 que trata dos partidos políticos.

Todavia, a título de esclarecimento e para um melhor entendimento acerca da temática proposta, é oportuno tratar dos antecedente históricos dos direitos e garantias fundamentais.

\section{ANTECEDENTES HISTÓRICOS}

Acerca da origem dos direitos e garantias fundamentais:

[...] a origem dos direitos individuais do homem pode ser apontada no antigo Egito e Mesopotâmia, no terceiro milênio a.C., onde já eram previstos alguns mecanismos para a proteção individual em relação ao estado. $O$ Código de Hamurabi (1690 a.C.) talvez seja a primeira codificação a consagrar um rol de direitos comuns a todos os homens, tais como a ida, a propriedade, a honra, a dignidade, a 
família, prevendo, igualmente, a supremacia das leis em relação aos governantes. (MORAES apud NUNES JUNIOR, 2011, p. 23).

Posteriormente, observa-se o surgimento de regras destinadas a tutelar certos direitos em relação aos abusos estatais, tanto na Grécia quanto no Direito Romano. Destaca-se ainda outro marco importante, isto é, o Cristianismo, considerado como um impulso relevante para a adoção de um ideal de dignidade do homem.

Todavia, como assevera o Professor Flávio Martins Alves Nunes Junior: "[...] o mais importante antecedente histórico das declarações de direitos humanos fundamentais é a Magna Charta Libertatum, de 1215, outorgada pelo rei João I, da Inglaterra (mais conhecido como João sem Terra). (NUNES JUNIOR, 2011, p. 23). A alcunha de "João sem Terra" se deve ao fato de que, ao nascer, João I não havia herdado nenhuma terra quando seu pai faleceu. E ao assumir o trono, de modo incidental em decorrência da morte de seu irmão, João I passou a aumentar de modo vertiginoso os tributos. Em virtude disto, João I foi pressionado pelos barões Ingleses a assinar um documento cuja finalidade era a limitar seus poderes, dando origem a chamada Magna Charta Libertatum.

Neste aspecto, aduz o professor Flávio Martins Alves Nunes Junior que:

Malgrado célebre, a Magna Chata Libertatum não foi respeitada por muitos ingleses. Por esse motivo, muitas outras leis surgiram nos século seguintes. Em 1628, a Petition of Rights previa que, dentre tanto outros direitos ali previstos, nenhum home livre ficasse sob prisão ou detido ilegalmente. Em 1679, o habeas corpus act regulamentou uma prática já existente na jurisprudência consistente em mandados (writes) de apresentação. Em 1689, a Bill of Rigths previa, dentre outros direitos, o princípio da legalidade, o direito de petição, liberdade de eleição dos membros do parlamento, vedação às penas cruéis etc. (NUNES JUNIOR, 2011, p. 24).

Neste sentido, observa-se que, em que pese exista uma grande importância do Cristianismo e o Direito Romano para a expressividade dos direitos e garantias fundamentais, foi a Magna Charta Libertatum que sedimentou uma ideologia mais fundamentada para a atual posição de tais garantias nos atuais ordenamentos jurídicos.

Direitos fundamentais e direitos humanos

Muitas vezes ocorre uma confusão conceitual acerca dos termos "direitos fundamentais" e "direitos humanos". Todavia, tal equívoco não pode vigorar. São termos que, embora semelhantes, são distintos.

Neste sentido, esclarece o professor Flávio Martins Alves Nunes Júnior:

"Direitos Humanos" é uma expressão costumeiramente utilizada em documentos internacionais, bem como "direitos do homem", que tratam da grande maioria dos direitos (que normalmente pertencem à pessoa humana), em contraposição aos direitos referentes às instituições, aos animais etc. São Sinônimas as expressões "direitos humanos" e "direitos fundamentais"? Embora parte da doutrina entenda que sim, poder-se-ia fazer a seguinte distinção: enquanto os primeiros estão previstos apenas pelo direito internacional, nos tratados internacionais etc., os segundos estão positivados na Constituição de cada Estado. (NUNES JUNIOR, 2011, p. 21).

A maior importância acerca de tal distinção reside no campo didático, haja vista que, quando se trata de eficácia, esta é diferente no que tange aos direitos humanos em relação aos direitos fundamentais.

\section{DIGNIDADE DA PESSOA HUMANA}

A Constituição da República Federativa do Brasil de 1988 aparece num âmbito de busca da defesa e da realização de direitos fundamentais do sujeito, quando individual, e da coletividade, nas mais distintas áreas, na qual elegeu o Estado Democrático de Direito como instituição de coordenação política do país, o qual se destina a garantir o exercício dos direitos sociais e individuais de cada cidadão, bem como o bem-estar, o desenvolvimento, a igualdade e a justiça social. Conforme Mezzaroba e Silveira:

O pensamento liberal criou as bases para o surgimento do Estado de Direito que, embora seja continuamente moldado, permanece nos pilares das construções dogmático-jurídicas pelo mundo. Assim, tradicionalmente debatemos e nos aprofundamos em algumas 
noções clássicas, como o pertencimento dos indivíduos a um Estado e o direito enquanto comando que visa ao interesse geral no âmbito de uma comunidade nacional. [...], o Estado-Nação está desafiado em sua hegemonia ao ter de conceber a cidadania no seu aspecto mais abrangente, não apenas como vínculo de fidelidade política, como era em sua origem. Nesse sentido, vislumbra-se uma nova forma de Estado que incorpora os valores comuns a todos os sujeitos de uma comunidade global e promove a defesa dos direitos humanos com apoio na dignidade da pessoa humana (2011, p. 443).

Seguindo a tendência deste constitucionalismo moderno, a Carta Política do país adotou expressamente ao seu texto constitucional, o princípio da dignidade da pessoa humana (CF art. $\left.1^{\circ}, \mathrm{III}\right)$, estabelecendo-a como um valor supremo, a qual serviu como fundamento da República Federativa do Brasil, ou seja, este princípio é o mais importante vetor presente nos diplomas jurídicos em vigor nos Estados, cuja missão é a preservação do ser humano, desde o nascimento até a morte, conferindo-Ihe autoestima e garantindo-lhe o mínimo existencial.

\section{DIGNIDADE DA PESSOA HUMANA COMO FUNDAMENTO DOS DIREITOS HUMANOS}

A discussão entre filósofos sobre o conteúdo da dignidade é bastante antiga no Ocidente, fruto de uma tradição e crença judaico-cristã do homem como imagem e semelhança de Deus. Comparato (2006, p. 479) explica que por intermédio do cristianismo a definição de pessoa foi produzida como substância, a propósito da figura de Jesus Cristo, em sua dupla condição de pessoa e de Filho de Deus. Ou seja, através deste entendimento se desenvolveu a noção de dignidade pessoal atribuída a cada indivíduo.

Porém, o movimento que mais contribuiu para o estudo do tema foram os jusnaturalistas, que tiveram como precursor Kant, o qual entendia que a "dignidade" tratava-se de um valor moral de interesse geral. Como valor moral, a dignidade não pode ser alienada como se faz com uma mercadoria. Dessa forma, preleciona Kant que "[...] o homem, e em geral todo ser racional, existe como fim em si mesmo, não só como meio para qualquer uso desta ou daquela vontade." (2000, p. 78). Ou seja, o homem é o fim e não o meio para alcançar quaisquer fins.
$\mathrm{Na}$ semelhante acepção, Comparato (1999, p. 20) afirma que a dignidade deve ser tratada como um fim em si, não como meio, e complementa que resulta do fato de que a pessoa juntamente com este princípio perdura em condições de autogoverno, podendo escolher viver pelas leis que ela própria edita.

Partindo desses pressupostos, faz-se necessário conceituar o que seja o princípio da dignidade da pessoa humana. Conforme Sarlet pode ser definida como:

[...] a qualidade intrínseca e distintiva de cada ser humano que o faz merecedor de mesmo respeito e consideração por parte do Estado e da comunidade, implicando, neste sentido, um complexo de direitos e deveres fundamentais que assegurem a pessoa tanto contra todo e qualquer ato de cunho degradante e desumano, como venham a garantir as condições existenciais mínimas para uma vida saudável, além de propiciar e promover sua participação ativa e co-responsável nos destinos da própria existência e da vida em comunhão dos demais seres humanos (2001, p. 60).

Seguindo este conceito, Oliveira (2009, p. 816) entende a dignidade da pessoa humana como um conjunto de atributos pessoais de natureza moral, intelectual, física, material que dão a cada indivíduo a consciência de suas carências, de suas aspirações, de seu valor, e o tornam merecedor de respeito e acatamento perante o corpo social.

Por esses conceitos, seja qual for o aspecto pelo qual o homem é analisado, percebe-se que ele é dotado de um valor de dignidade, que consiste em sua autonomia, devido estar apto para formular as próprias regras de vida. Esta dignidade está intrínseca no indivíduo pelo simples fato de ele existir, ou seja, "[...] todo indivíduo é agente legítimo para buscar sua dignidade em face do Estado ou outro sujeito, [...], pelo simples fato de ser pessoa humana." (MEZZAROBA; SILVEIRA, 2011, p. 446).

Entretanto, com o avanço das normas que tutelam os direitos humanos, percebe-se que a ligação entre a dignidade e direitos do homem, somente aconteceu com o surgimento dos grandes tratados internacionais e com as Constituições subsequentes a Segunda Grande Guerra Mundial.

O ressurgimento jurídico da dignidade no 
pós-guerra confirmou uma reação histórica contra os movimentos totalitários que infringiram de forma sistematizada a própria dignidade, na tentativa de formar um projeto de conceituar o ser humano a partir de seus requisitos, na qual ele era visto como um problema.

Por este ponto de vista, sobre a exclusão do indivíduo, que permaneceu durante o governo nazista, trouxe grande ascensão à dignidade enquanto valor vital do homem. Dessa forma, por mais dura e cruel que foi a Segunda Guerra Mundial, trouxe ao mundo um novo momento histórico, de modo que despertou as políticas internacionais a se preocuparem mais com os direitos fundamentais. Assim, construiu-se a noção de Direito Internacional dos Direitos Humanos com base no Tribunal de Nuremberg, na constituição da ONU e na exposição da Declaração Universal dos Direitos Humanos.

Logo, parte-se do pressuposto que os direitos humanos se preocupam com a satisfação das carências humanas privativas de cada indivíduo. Neste sentido, afirma Nader que "apesar de possuir um substrato axiológico permanente, que reflete a estabilidade da 'natureza humana', o direito é um engenho à mercê da sociedade e deve ter a sua direção de acordo com os rumos sociais." (2004, p. 17). Tomando isto como base é que surge a noção do binômio necessidade/ direito para a constituição de normas jurídicas, na qual servirão para impor certos limites à liberdade do homem, mediante a determinação de certas condutas para a convivência em sociedade. Consoante a isto, Silveira expressa que:

[...] os direitos nascem e se modificam obedecendo a um núcleo formado pelo sentimento axiológico da sociedade, o qual a partir de um dado fato se adere um determinado valor, que, por sua vez, passa a ser normatizado tanto internacional como nacionalmente pelos Estados, com indispensável fundamento na idéia de dignidade da pessoa humana. (2008 apud. MEZZAROBA; SILVEIRA, 2011, p. 447).

Portanto, com o passar dos anos e o desenvolvimento das sociedades, o direito deve sempre se renovar frente à mobilidade social, de forma que venha satisfazer os anseios incorporados ao meio público.

Traçando um estudo histórico quanto aos elementos que compõem os direitos humanos, foi somente em 1948, através da Declaração
Universal dos Direitos do Homem, que a dignidade da pessoa humana assumiu o caráter de pilar de todos os direitos fundamentais do homem.

Percebe-se que a dignidade da pessoa humana aparece atualmente em vários textos constitucionais. No Brasil, pode-se dizer que ela é o ponto central da ordem jurídica, visto que o constituinte de 1988 colocou-a na posição de princípio fundamental da República, pilar substancial da organização do país, em concordância com o que prevê o inciso III do art. $1^{\circ}$ da Constituição da República Federativa do Brasil de 1988.

Assim sendo, observa-se que os direitos fundamentais tomaram grande proporção no sentido de proteger o indivíduo em sua dignidade, pois esta, enquanto critério de integração do ordenamento jurídico, servirá como fundamento de todos os direitos ligados ao homem á medida que for incorporada ao complexo constitucional do país.

\section{DISPOSITIVOS CONSTITUCIONAIS}

A Constituição da República Federativa do Brasil de 1988, objetivando efetivar o princípio da dignidade da pessoa humana, estipula um encadeamento de direitos e garantias fundamentais às pessoas com deficiência.

Expressa a Carta Política do país, em seu Artigo $5^{\circ}$, que "todos são iguais perante a lei, sem distinção de qualquer natureza, garantindo-se aos brasileiros e aos estrangeiros residentes no País a inviolabilidade do direito à vida, à liberdade, à igualdade, à segurança e à propriedade [...]" (BRASIL, 1988). Conforme dispõe o texto constitucional, o Governo deve ao menos assegurar condições mínimas de subsistência de seus cidadãos, como por exemplo, garantir uma alimentação adequada, moradia, vestuário, saúde, educação, cultura, profissão e o lazer, ou seja, assegurar um mínimo de dignidade para cada cidadão.

Este dispositivo, ora citado, vem tratar do princípio constitucional da igualdade, que deve ser investigado e utilizado como critério para a aplicação de quaisquer normas, de modo que viabilize um tratamento isonômico a todos, sem ressalva.

Por meio de uma interpretação extensiva da respectiva norma, percebe-se que o texto constitucional não fica limitado apenas à acep- 
ção formal, como literalmente é encontrado na ordem jurídica, mas que deve ser compreendido em sua totalidade, envolvendo assim o sentido material da lei. Assim sendo, a verdadeira isonomia ocorre quando se trata os iguais de maneira igual e os desiguais de maneira desigual na medida de suas desigualdades.

Ao prever tal princípio na Constituição Federal, percebe-se que o legislador estabeleceu uma forma que viesse elevar as pessoas com deficiência ao nível daquelas que não possuem algum tipo de debilidade, por meio de proteções constitucionais. Fato este que faz com que as pessoas que sofrem por alguma necessidade especial busquem mais o apoio da sociedade e de políticas públicas destinadas em assegurar seus direitos.

No tocante aos direitos sociais, em específico àqueles dos trabalhadores, expressa a Carta Magna do país em seu art. $7^{\circ}$, inc. XXXI que "são direitos dos trabalhadores urbanos e rurais, além de outros que visem à melhoria de sua condição social: [...] proibição de qualquer discriminação no tocante a salário e critérios de admissão do trabalhador portador de deficiência." (BRASIL,1988). Nesta linha de pensamento, preleciona Aldacy Rachid Coutinho que:

Não se trata de incluir os excluídos, mas de não os excluir, pelo que há de se rechaçar a guetização da sociedade, permitindo sempre a integração no limite possível, porquanto todos são cidadãos e devem participar em igualdade de oportunidades. A solidariedade constitucional determina a incorporação das diferenças no padrão de normalidade e, assim, a superação de todas as barreiras da exclusão para o acolhimento das demandas, com o rompimento da igualdade formal e não uma simples adaptação para convivência segundo padrões ditados aos não portadores de deficiência (2013, p. 622).

Em se tratando das competências administrativas de cada ente federativo, a Lei Maior estabelece em seu art. 23, II, que compete tanto a União quanto aos Estados e Municípios "cuidar da saúde e assistência pública, da proteção e garantia das pessoas portadoras de deficiência." (BRASIL, 1988). Além da atribuição em executar a letra constitucional, a Carta Política prevê que cabe a todos estes entes legislarem concorrentemente sobre a "[...] proteção e integração social das pessoas portadoras de defici- ência." (BRASIL, 1988), ou seja, a preocupação em fixar essas instruções servirá para igualar os deficientes as pessoas que não sofrem por nenhuma necessidade especial. Por este raciocínio, afirma Almeida que:

A Constituição de 1988 dedicou vários comandos à questão dos portadores de deficiência. E para melhor organizar a atuação conjunta dos entes federados no cumprimento das tarefas de sua alçada no setor, as normas gerais norteadoras serão postas pela União e suplementadas pelos demais. (2013, p. 755).

Concernente à sistematização do Estado quanto à administração pública, dispõe a Magna Carta no art. 37 que:

A administração pública direta e indireta de qualquer dos Poderes da União, dos Estados, do Distrito Federal e dos Municípios obedecerá aos princípios de legalidade, impessoalidade, moralidade, publicidade e eficiência e, também ao seguinte: [...] a lei reservará percentual dos cargos e empregos públicos para as pessoas portadoras de deficiência e definirá os critérios de sua admissão (2010, p. 41).

Com a análise dos dispositivos constitucionais até aqui estudados, percebe-se que as diretrizes traçadas pela Lei Suprema em favor do Estado, assemelha-se diretamente com o princípio da dignidade da pessoa humana e o da igualdade. Entretanto, nem sempre essas garantias constitucionais são cumpridas como deveriam, isto se dá por falta de observância desses princípios, o que reforça a necessidade de um policiamento cada vez mais massiva.

No que discerne a educação, a Constituição da República expressa em seu artigo 208, que o Estado prestará seu dever com a educação por meio da garantia de auxílio educacional especializado as pessoas que sofrem de necessidades especiais, preferencialmente na rede regular de ensino, além de possibilitar o ingresso aos níveis mais elevados do ensino, da pesquisa e da criação artística, em conformidade com a capacidade de cada indivíduo.

A Lei das Leis institui ainda ao Estado a obrigação de assegurar o acesso e a gratuidade no ensino público, visto que a educação constitui princípio de fundamental relevância para a 
formação de uma sociedade sólida e desenvolvida nas diversificadas áreas sociais. Passa a ter maior relevância e qualidade no sistema educacional quando se trata da formação de pessoas com necessidades especiais.

Tentando atender este embate, o legislador constituinte se preocupou em alojar na Lei Maior a garantia do ensino a todos, sem haver quaisquer discriminações. Por consequência disto, percebe-se que esses dispositivos constitucionais são de fundamental importância, porque buscam confirmar cada vez mais a definição de inclusão, que permite ao cidadão com algum tipo de debilidade, possa desenvolver suas habilidades conforme seus atributos pessoais, que devem ser reverenciadas pelo sistema político do país e pelo corpo social.

É tratada no Capítulo VII da Magna Carta de 1988 a família, a criança, o adolescente e o idoso, desta maneira, integram-se também as pessoas que padecem de necessidades especiais. Enuncia o art. 227 da respectiva Lei que:

É dever da família, da sociedade e do Estado assegurar à criança e ao adolescente, com absoluta prioridade, o direito à vida, à saúde, à alimentação, à educação, ao lazer, à profissionalização, à cultura, à dignidade, ao respeito, à liberdade e à convivência familiar e comunitária, além de colocá-los a salvo de toda forma de negligência, discriminação, exploração, violência, crueldade e opressão. $\S 1^{\circ}-\mathrm{O}$ Estado promoverá programas de assistência integral à saúde da criança $e$ do adolescente, admitida a participação de entidades não governamentais e obedecendo os seguintes preceitos: [...] II - criação de programas de prevenção e atendimento especializado para os portadores de deficiência física, sensorial ou mental, bem como de integração social do adolescente portador de deficiência, mediante o treinamento para o trabalho e a convivência, e a facilitação do acesso aos bens e serviços coletivos, com a eliminação de preconceitos e obstáculos arquitetônicos. $\S 2^{\circ}$ - A lei disporá sobre normas de construção de logradouros e edifícios de uso público e de fabricação de veículos de transporte coletivo, a fim de garantir o acesso adequado às pessoas portadoras de deficiência (BRASIL, 1988).

O deficiente, seja qual for a sua necessidade especial, auferiu um tratamento sui generis da Carta Mãe. Interpreta Morais e Teixeira que o caput deste artigo também é aplicado aos deficientes, a qual emanou direitos fundamentais específicos. Esta explicação se dá por dois fundamento:

O primeiro se baseia no fato de ser ele, assim como a criança e o adolescente, portador de vulnerabilidade e nessa qualidade, necessita da atuação especial do Estado, da família e da sociedade; a segunda, de ordem formal, funda-se no fato de a ele ser atribuídos direitos, previstos nos parágrafos do art. 227, que devem estar em consonância com o caput do mesmo dispositivo, sob pena de ferir a coerência do ordenamento jurídico." (MORAIS e TEIXEIRA, 2013, p. 2136).

Pelo que foi expresso até este certo momento, conclui-se que além de outros aparatos assegurados pela Constituição Federal do país, a pessoa que carece de algum desenvolvimento, seja ele intelectual ou funcional, não pode ser tratada como alguém que esteja em desigualdade com o seu próximo. Tem de esta minoria ser encorajada, de modo que venha desenvolver ainda mais seus potenciais.

\section{PRINCÍPIO DA IGUALDADE}

No caput do artigo $5^{\circ}$ da Constituição Federal de 1988 quando logo no início proclama: "Todos são iguais perante a lei [...]", estampa ai o princípio da igualdade, mais especificamente o da igualdade formal. Vale ressaltar que incido I do referido artigo também é de importância basilar para o princípio da igualdade. (2013):

Conforme afirma Leonardo Martins

[...] o preceito constitucional da igualdade é o parâmetro para aplicação da lei infraconstitucional, que não poderá fazer "distinção de qualquer natureza". A exposição significa que os órgãos públicos não poderão fazer distinção quando da aplicação da lei ordinária e segure a igualdade neste contexto é, conforme já salientado, igualdade em sentido formal, pois implica proibição de distinção, vale dizer, de diferenciação formal, pelo aplicador do direito (Administração e Judiciário) que não tenha correlato no texto da lei

Seguindo o mesmo pensamento do autor supracitado, a igualdade formal está intrinsicamente ligada ao princípio da legalidade (inciso 
II, artigo $5^{\circ}, \mathrm{CF} / 88$ ), não podendo o aplicador do direito se tratar de maneira desigual aquilo que a lei não fixou.

Porém, "o princípio da igualdade não veda o tratamento discriminatório entre indivíduos, quando há razoabilidade para a discriminação" (PAULO; ALEXANDRINO, 2015, p. 123). Segundo tal entendimento estamos diante doutro sentido do princípio da igualdade, o sentido material. E tal entendimento já foi firmado pela nossa Suprema Corte.

Em julgamentos históricos, como o da ADPF 186/DF que teve como relator o MM. Ministro Ricardo Lewandowski, foi declarada constitucional os atos da Universidade de Brasília de reservar $20 \%$ das vagas por critério étnico-social. No mesmo diapasão temos o julgamento da formação de famíia homoafetiva, ADPF 4.277/ DF, onde o Exímio relator foi o Ministro Ayres Britto, em tal situação o Supremo Tribunal Federal reconheceu a formação de família por casais do mesmo sexo.

Outro julgamento tratando do time foi a ADC 19/DF, relator Marco Aurélio, e sobre ela os brilhantes comentários de Marcelo Alexandrino e Vicente Paulo:

Ao reconhecer a constitucionalidade da Lei Maria da Penha, o STF deixou assente que, ao criar mecanismos específicos para coibir e prevenir a violência doméstica contra a muIher e estabelecer medidas especiais de proteção, assistência e punição, tomando como base o gênero da vítima, o legislador teria utilizado meio adequado e necessário para fomentar a finalidade traçada pelo art. 226, $\S 8^{\circ}$, da Constituição Federal. (ALEXANDRINO; PAULO, 2015, p. 124).

E continuam:

Destacando a incidência do princípio da proteção insuficientes dos direitos fundamentais, aduziu o Tribunal Excelso, ainda, não ser desproporcional ou ilegítimo o uso do sexo como critério de diferenciação, visto que a mulher seria eminentemente vulnerável no tocante a constrangimentos físicos, morais e psicológicos sofridos em âmbito privado. (ALEXANDRINO; PAULO, 2015, p. 124).

Diante do exposto, é de se concluir que não resta dúvida sobre a legitimidade das normas que tratam dos deficientes, uma vez que há uma razoabilidade para tal, não deixando bre- chas para entendimentos fúteis de que é quebrado o princípio da igualdade quando se diferencia uma pessoa com deficiência para uma sem deficiência, sendo que para determinadas situações e atividades deve haver tal discriminação.

\section{NATUREZA JURÍDICA DOS DISPOSITIVOS CONSTITUCIONAIS ATINENTES AOS DIREI- TOS DAS PESSOAS COM DEFICIÊNCIA}

Discussões são levantadas acerca da natureza jurídico-constitucional dos dispositivos constitucionais atinentes aos direitos das pessoas com deficiência. Isto é, tais dispositivos, tecnicamente, podem ser considerados direitos fundamentais? O presente questionamento surge em virtude do fato que, com exceção do artigo $7^{\circ}, \mathrm{XXX}$, todos os outros dispositivos que dizem respeito à pessoa com deficiência estão dispostos fora do título II da Constituição Federal, sob o nome de "Direitos e Garantias Fundamentais".

Sabe-se que, direitos fundamentais se originam da positivação dos chamados direitos humanos em determinada Constituição, e desse modo, por meio de um silogismo, nota-se que, pelo fato dos supracitados artigos disporem sobre um patamar existencial mínimo para as pessoas com deficiência, poder-se-ia concluir que sim, são direitos fundamentais, pois são direitos humanos positivados na CF/88. Todavia, embora lógico, o pensamento é insuficiente, se faz necessário, para tanto, uma análise mais pormenorizada acerca da temática.

Portanto, aqueles artigos dispostos fora do título II da CF/88 podem ser considerados direitos fundamentais? Se sim, qual o fundamento?

Neste aspecto, leciona Pedro Lenza:

Iniciamos os estudos pelos direitos e deveres individuais e coletivos, lembrando, desde já, como manifestou o STF, corroborando com a doutrina mais atualizada, que os direitos e deveres individuais e coletivos não se restringem ao art. $5^{\circ}$ da $\mathrm{CF} / 88$, podendo ser encontrados ao longo do texto constitucional, expressos ou decorrentes do regime e dos princípios adotados pela Constituição, ou, ainda, decorrentes dos tratados e convenções internacionais de que o Brasil seja parte. (LENZA, 2013, p. 2027).

De modo semelhante, Alves Júnior discorre que: 
O Supremo Tribunal Federal, na ADI n 939, excluiu a tese de que "direitos e garantias individuais" estariam circunscritos ao art. $5^{\circ}$ da Constituição Federal. O Mesmo ocorreu na ADIn 3685, julgada em 2006, acerca da Emenda Constitucional 52, que alterou o art. 17 da Constituição Federal. [...]. Na primeira ADIn (939-7), o Supremo Tribunal Federal considerou que o princípio da anterioridade tributária, insculpido no artigo 150 da Constituição Federal é cláusula pétrea, por ser um direito individual do contribuinte. (NUNES JUNIOR, 2011, p. 89).

Tendo vista as considerações supramencionadas, torna-se evidente que os direitos e deveres individuais e coletivos não se restringem ao artigo $5^{\circ}$ da Constituição Federal, haja vista que, como dissertado pelo Professor Pedro Lenza, estes podem decorrer de princípios ou tratados adotados pela CF/88.

Desse modo, os dispositivos atinentes aos direitos das pessoas com deficiência são considerados direitos fundamentais pelo fato que encontram legitimidade no princípio da igualdade, plasmado no artigo $5^{\circ}$ da Constituição Federal., como já exposto no presente estudo.

A igualdade, fundamentadora desses dispositivos, trata-se mormente daquela chamada "igualdade material", presente da obra "Oração aos Moços" de Rui Barbosa, onde este afirma que, não basta que a lei trate todos de maneira igual, é preciso que a lei trate os iguais de maneira igual e os desiguais de maneira desigual na medida de suas desigualdades, de modo que aproxime do ideal de justiça.

Nota-se que, a CF/88, ao dispor sobre os direitos das pessoas com deficiência, visa conferir uma série de direitos a estes cidadãos, de modo que, no plano concreto, possam agir em pé de igualdade com os demais cidadãos sem limitações físicas ou intelectuais.

O maior reflexo disso reside no fato que, se tais direitos são considerados como fundamentais, eles também passam a gozar de alguns "privilégios" previstos pela CF/88, tal como o fato de serem considerados cláusulas pétreas, em virtude da previsão do artigo $60, \S 4^{\circ}$, IV, onde diz que não serão propostas emendas constitucionais que visem abolir os direitos e garantias fundamentais.

\section{CONSIDERAÇÕES FINAIS}

Diante do exposto pode-se concluir que, em que pese os dispositivos constitucionais supracitados não estejam dispostos dentro do título II da CF/88, eles podem sim ser considerados direitos fundamentais. Haja vista que, como bem dissertado pelos autores citados no presente estudo, os direitos e garantias fundamentais não se restringem ao artigo $5^{\circ}$ ou ao título II da CF/88. Eles podem ser decorrentes de tratados que o Brasil seja parte, bem como de princípios albergados pela Constituição Federal de 1988. Deste modo, pelo fato de, os direitos das pessoas com deficiências decorrerem justamente do princípio da igualdade, previsto este pela CF/88, estes podem ser considerados direitos fundamentais, e deste modo, gozar das vantagens inerentes a estes.

Tendo o princípio da igualdade grande importância para isso, uma vez que o aplicador do direito não poderá se desviar do que está na lei, caso a lei não preveja desigualdade, desigualdade ali não haverá. Mas, tal entendimento não impossibilita o legislador de discriminar, desde de que haja razoabilidade para tal. Como já foi debatido no tópico reservado ao princípio da igualdade, o Supremo Tribunal Federal já firmou e considerou constitucional o entendimento de que pode haver discriminação deste que por justo motivo, como por exemplo a Lei Maria da Penha, as cotas étnico-sociais ou os casais homoafetivos constituírem família.

\section{REFERÊNCIAS}

BRASIL. Constituição (1988). Constituição da

República Federativa do Brasil: promulgado em 5 de outubro de 1988. Brasília: Senado Federal, 1988.

COMPARATO, F. K. A afirmação histórica dos direitos humanos. São Paulo: Saraiva, 1999.

Ética, direito, moral e religião no mundo moderno. São Paulo: Companhia das Letras, 2006.

CANOTILHO, J. J. G. et al. Comentários à Constituição do Brasil. São Paulo: Saraiva/ Almeida, 2013. 2380 p.

NUNES JUNIOR, F. M. A. Remédios

Constitucionais. 4. ed. São Paulo: Revista dos 
CEBRIAN et al.

Tribunais, 2011.

KANT, I. Fundamentos da metafísica dos

costumes. São Paulo: Ediouro, 2000.

NADER, P. Introdução ao estudo do direito.

24. ed. Rio de Janeiro: Forense, 2004.

PAULO, V.; ALEXANDRINO, M. Direito

Constitucional Descomplicado. 14. ed. São

Paulo: Método, 2015.

SARLET, I. W. Dignidade da pessoa humana

e direitos fundamentais. Porto Alegre: Livraria

do Advogado, 2001.

OLIVEIRA, A. C. M. de. O direito penal e a

dignidade humana. A questão criminal: discurso

tradicional. In: Tratado luso-brasileiro da

dignidade humana, 2. ed. MIRANDA, J.;

SILVA, M. A. M. da. São Paulo: Quartier Latin,

2009.

\section{DISPOSITIVOS CONSTITUCIONALES RELATIVOS A LOS DERECHOS DE LAS PERSONAS CON DISCAPACIDAD}

Resumen: El respectivo estudio ha buscado reflexionar sobre los dispositivos constitucionales relativos a los derechos de las personas con discapacidad, así como la naturaleza jurídica constitucional de éstos. De este modo, por medio de un análisis descriptivo con un abordaje cualitativo, el presente trabajo dispondrá sobre los artículos insertados en la Constitución Federal de 1988 que tratan sobre la situación de las personas que, en virtud de sus limitaciones, poseen su movilidad, o capacidad intelectual reducida. Se hará un breve análisis sobre lo que se trata de los derechos y garantías fundamentales, así como se tendrá en cuenta la importancia del principio de la dignidad de la persona humana dentro del ordenamiento jurídico patriótico. Se observa que, como método de investigación, se ha utilizado básicamente la investigación legislativa bibliográfica acerca de la temática, con autores especializados en el tema. Por último, habida cuenta del debido levantamiento bibliográfico, se concluyó que, en que pese a que parte de estos dispositivos estén situados fuera del Título II de la CF / 88, aun así, pueden ser considerados derechos fundamentales en virtud del principio de igualdad.

Palabras Clave: Constitución Federal; Derechos Fundamentales; Dignidad de la Persona Humana; Persona con discapacidad. 